\title{
Study on the Influence of Saturated Aliphatic Dicarboxylic Acids on the Solubility of Their Norfloxacin Salts
}

\author{
Lihua Zhu', Dong Huang'2, Chengjun Jiang2* \\ ${ }^{1}$ Taizhou Institute of Measurement Technology, Taizhou, China \\ ${ }^{2}$ School of Biological and Chemical Engineering, Zhejiang University of Science and Technology, Hangzhou, China \\ Email: ^jcj312@zust.edu.cn
}

How to cite this paper: Zhu, L.H., Huang, D. and Jiang, C.J. (2020) Study on the Influence of Saturated Aliphatic Dicarboxylic Acids on the Solubility of Their Norfloxacin Salts. Open Access Library Journal, 7: e6650. https://doi.org/10.4236/oalib.1106650

Received: July 23, 2020

Accepted: October 6, 2020

Published: October 9, 2020

Copyright $\odot 2020$ by author(s) and Open Access Library Inc.

This work is licensed under the Creative Commons Attribution International License (CC BY 4.0).

http://creativecommons.org/licenses/by/4.0/

\section{(c) (i) Open Access}

\begin{abstract}
The crystallization of norfloxacin, an antibacterial fluoroquinolone compound, with different saturated aliphatic dicarboxylic acids yields five novel pharmaceutical salts via molecular recognition. In particular, a new norfloxacin-glutaric acid salt was obtained, which was characterized by infrared spectroscopy and powder X-ray diffraction. The effect of $\mathrm{pKa}$ on the solubility and dissolution profile of drug salts are investigated in pure water. After the formation of salts, the solubility increases at near neutral $\mathrm{pH}$ in all cases. Glutaric acid shows evidence of a good candidate to enhance the solubility of fluoroquinolone drugs for the solubility of 1 is approximately 27.7 times as large as that of norfloxacin in pure water.
\end{abstract}

\section{Subject Areas}

Chemical Engineering \& Technology

\section{Keywords}

Norfloxacin, Dicarboxylic Acid, Solubility, Crystal

\section{Introduction}

Salt formation is one of the effective means to improve the physicochemical properties of drug molecules and improve their pharmaceutical properties, which can change the solubility of drugs, improve their compliance, improve their stability and reduce their adverse reactions. In drug development, salt formation can also be used to extend the patent protection period of drugs or circumvent their patent protection [1]. In the development of salt-forming drugs, the factors such as pKa value and safety of acid or base used for salt formation, administration 
route and dosage form after salt formation, homoionic effect, etc. should be considered comprehensively, and the key is to select the appropriate salt form [2] [3]. Norfloxacin (NFX) is potent fluoroquinolone antibacterial compounds, which are widely used in the treatment of various bacterial infections [4]. NFX has low solubility and poor permeability at neutral pH (BCS class IV) [5]. In order to change its water solubility and increase its bioavailability, succinic acid, malonic acid, and maleic acid salts and isonicotinamide cocrystal were successively synthesized [6]. NFX fumarates [7] showed a moderate 3-fold enhancement in solubility. Norfloxacin with artificial sweeteners such as saccharin and acesulfame salts [8]. NFX salts with benzenedicarboxylic acids, the aqueous solubility of NFX is increased after the formations of all salts except terephthalate [9]. Multidrug salt forms of NFX with nonsteroidal anti-inflammatory drugs [10]. Saccharin salts of NFX [11]. Drug-Drug Salt Hydrate of Norfloxacin and Sulfathiazole [12]. However, the literature has not systematically studied the effect of acid salting with it on its solubility. It could be anticipated that NFX drugs with linear saturated dicarboxylic acids may have a considerable improvement in solubility and it is also reasonable to speculate that the higher solubility of the salts could translate into higher bioavailability. In this contribution, we demonstrate the syntheses, characteristics, and solubility of pharmaceutical salts assembled by zwitterionic hydrogen-bonding interactions between NFX and diverse linear saturated dicarboxylic acids (Figure 1).

\section{Experimental Section}

\subsection{Materials}

Norfloxacin (NFX, purity > 99\%) was purchased from Zhejiang Lepu Pharmaceutical Co., Ltd. Saturated aliphatic dicarboxylic acids, which are anhydrous oxalic acid (OXA, purity $\geq 99 \%$ ), malonic acid (MAL, purity > 99.5\%), succinic acid (SUC, purity $>99.5 \%$ ), glutaric acid (GLU, purity $>99 \%$ ) and adipic acid(ADI, purity $>99 \%$ ), were purchased from Energy Chemical. Potassium bromide (purity $\geq 99.5 \%$, FTIR grade) was purchased from Aladdin.

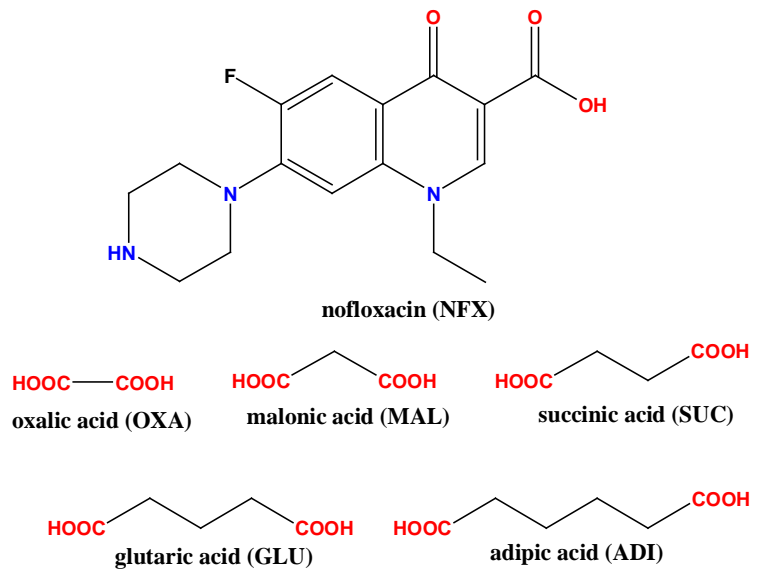

Figure 1. Structures of norfloxacin and saturated aliphatic dicarboxylic acids used in the study. 
Methanol (purity $\geq 99.5 \%$ ), ethanol (purity $\geq 99.7 \%$ ) and acetonitrile (purity $\geq$ 99\%) were purchased from Shanghai Lingfeng Chemical Reagent Co., Ltd.

\subsection{Salt Preparation}

1) Grinding Experiments. Approximately 200 - $400 \mathrm{mg}$ mixture of NFX and acid were added according to 1:1, 2:1 and 1:2 stoichiometric ratios in an agate mortar. After grinding evenly without liquid, two drops of purified water were added to grinding for about $10-15$ minutes. The resulting powder was air-dried and then stored in sample bottles.

2) Single-Crystal Growth. About $8 \mathrm{~mL}$ of purified water, methanol, ethanol and acetonitrile with different volume ratios were added into the above bottles as solvents, heated to dissolve completely, and then naturally cooled to room temperature and evaporated to crystallize. After the solution was crystallized and filtered, the resulting crystals were washed with a few drops of purified water and air-dried naturally.

\subsection{Characterization Methods}

1) Fourier Transform Infra-Red Spectroscopy. A Bruker VERTEX 70 Fourier infrared spectrometer and potassium bromide tabletting method were used in this paper, with the scanning wavenumber range $4000-400 \mathrm{~cm}^{-1}$ and the resolution of $4 \mathrm{~cm}^{-1}$.

2) Powder X-ray Diffraction. The Ultima IV X-ray diffractometer of Japan Science was selected for scanning and analysis under the parameters of radiation source $\mathrm{Cu} / \mathrm{Ka}(\lambda=0.154 \mathrm{~nm})$, power supply setting of $40 \mathrm{kV}, 40 \mathrm{~mA}$, 2theta scanning range of $5^{\circ}-40^{\circ}$, scanning step of $0.04^{\circ}$, and scanning speed of $5^{\circ} / \mathrm{min}$.

\subsection{Solubility Studies}

1) Drawing of Standard Curve. A sufficient amount (70 mg) of NFX was placed in a $250 \mathrm{~mL}$ volumetric flask, purified water was added to the calibration line, placed in a constant temperature shaker at $25^{\circ} \mathrm{C}$ and $150 \mathrm{rpm}$ for $24 \mathrm{~h}$, filtered, and the obtained solid was dried to constant weight in DHG Series Heating and Drying Oven (Shanghai Jinghong, China), and the remaining solid was weighed at $24 \mathrm{mg}$. The filtrate with the concentration of $0.184 \mathrm{mg} / \mathrm{mL}$ was diluted to $50 \mathrm{~mL}$ by measuring $0.5,0.8,1.1,1.4$ and $1.7 \mathrm{~mL}$ of filtrate. The standard curve was drawn by measuring the absorbance of UV-5500PC spectrophotometer (Metash, China) at $\lambda_{\max } 276 \mathrm{~nm}$ (Figure 2). The linear regression equation $y$ $=0.1175 x+0.0085$ and $R^{2}=0.9993$ were obtained.

2) Determination of Salt Solubility. Each group of NFX salts, which were excessively powdered, were suspended in $4 \mathrm{~mL}$ of water in spiral-capped glass bottles. These vials were placed in a TS-2102C constant temperature shaker (Shanghai Tiancheng, China) at $25^{\circ} \mathrm{C}$ and $150 \mathrm{rpm}$ for 72 hours, and then rested for another 72 hours. The filtrate was filtered with a disposable $2.5 \mathrm{~mL}$ sterile syringe and a filter head of $0.45 \mu \mathrm{m}$. The filtrate was collected and fully diluted. 
The apparent water solubility was calculated by measuring the absorbance of each group of NFX salts in water using Metash UV-5500PC spectrophotometer at $\lambda_{\max } 276 \mathrm{~nm}$.

\section{Results and Discussion}

\subsection{Screening Experiments}

NFX salts with oxalic acid, malonic acid, succinic acid, and adipic acid were prepared, and their crystal structures were determined [6] [13] [14]. Here we screening NFX-GLU by cooling crystallization. Screening process were shown in Table 1.

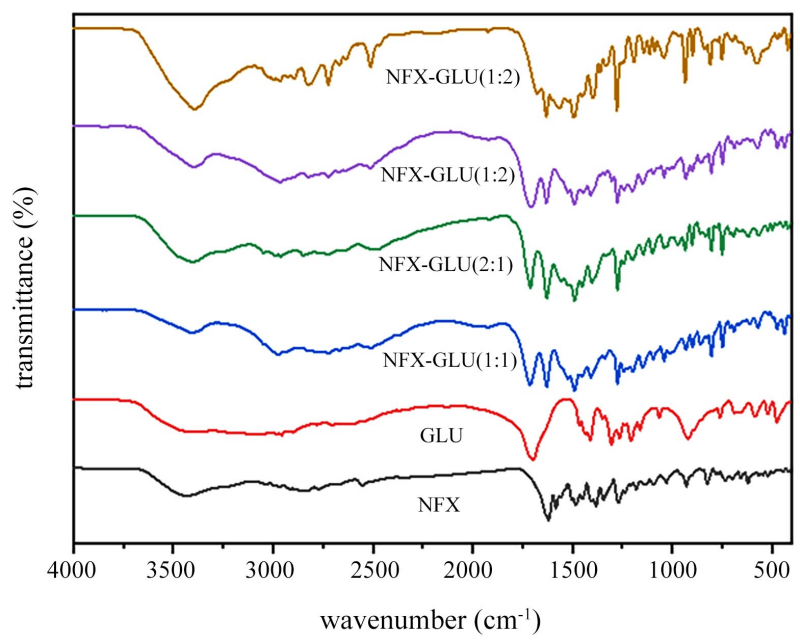

Figure 2. FTIR spectra of NFX, GLU, and their salts of 3 ratios.

Table 1. Screening process of norfloxacin glutarate.

\begin{tabular}{cccc}
\hline Ratio(NFX-GLU) & solvent & crystallization & suitable for SCXRD \\
\hline $1: 1$ & $\mathrm{H}_{2} \mathrm{O}$ & $\times$ & $\times$ \\
$1: 1$ & $\mathrm{H}_{2} \mathrm{O}-\mathrm{CH}_{3} \mathrm{OH}(1: 1)$ & $\times$ & $\times$ \\
$1: 1$ & $\mathrm{H}_{2} \mathrm{O}-\mathrm{CH}_{3} \mathrm{OH}(1: 3)$ & $\sqrt{ }$ & $\times$ \\
$2: 1$ & $\mathrm{H}_{2} \mathrm{O}-\mathrm{C}_{2} \mathrm{H}_{5} \mathrm{OH}(1: 3)$ & $\sqrt{ }$ & $\times$ \\
$2: 1$ & $\mathrm{H}_{2} \mathrm{O}$ & $\times$ & $\times$ \\
$2: 1$ & $\mathrm{H}_{2} \mathrm{O}-\mathrm{CH}_{3} \mathrm{OH}(1: 1)$ & $\times$ & $\times$ \\
$2: 1$ & $\mathrm{H}_{2} \mathrm{O}-\mathrm{CH}_{3} \mathrm{OH}(1: 3)$ & $\sqrt{ }$ & $\times$ \\
$1: 2$ & $\mathrm{H}_{2} \mathrm{O}-\mathrm{C}_{2} \mathrm{H}_{5} \mathrm{OH}(1: 3)$ & $\sqrt{ }$ & $\times$ \\
$1: 2$ & $\mathrm{H}_{2} \mathrm{O}$ & $\times$ & $\times$ \\
$1: 2$ & $\mathrm{H}_{2} \mathrm{O}-\mathrm{CH}_{3} \mathrm{OH}(1: 1)$ & $\times$ & $\times$ \\
$1: 2$ & $\mathrm{H}_{2} \mathrm{O}-\mathrm{CH}_{3} \mathrm{OH}(1: 3)$ & $\sqrt{ }$ & $\times$ \\
$1: 2$ & $\mathrm{H}_{2} \mathrm{O}-\mathrm{C}_{2} \mathrm{H}_{5} \mathrm{OH}(1: 3)$ & $\sqrt{ }$ & $\sqrt{ }$ \\
$1: 2$ & $\mathrm{H}_{2} \mathrm{O}-\mathrm{CH}_{3} \mathrm{CN}_{-} \mathrm{CH}_{3} \mathrm{OH}(1: 2: 1)$ & $\sqrt{ }$ & $\times$ \\
$1: 2$ & $\mathrm{H}_{2} \mathrm{O}-\mathrm{CH}_{3} \mathrm{CN}_{-}-\mathrm{CH}_{3} \mathrm{OH}(2: 1: 1)$ & $\times$ & $\times$ \\
\hline & $\mathrm{H}_{2} \mathrm{O}-\mathrm{CH}_{3} \mathrm{CN}_{-}-\mathrm{CH}_{3} \mathrm{OH}(1: 1: 2)$ & $\times$ & \\
\hline & & & $\times$ \\
\hline
\end{tabular}




\section{2. (Fourier Transform Infrared Spectromete, FTIR) Analysis}

FTIR spectra of NFX, GLU, and their salts were shown in Figure 2.

Among the salts formed by different ratios of NFX and GLU, the stretching vibration $3434 \mathrm{~cm}^{-1}$ absorption peak of N-H originally attributed to the NFX piperazine ring was red shifted to different degrees. When the two were mixed 1:1, the absorption peak at this point was $3403 \mathrm{~cm}^{-1}, 3401 \mathrm{~cm}^{-1}$ at $2: 1$, and $3398 \mathrm{~cm}^{-1}$ at $1: 2$, in which the red shift is most obvious when mixing with $1: 2$, while there is no obvious change in the characteristic band region $1600-1750 \mathrm{~cm}^{-1}$ of the carbonyl part of NFX and NFX-GLU. This suggests that the protons on the GLU carboxyl group may transfer to the $\mathrm{N}-\mathrm{H}$ of the NFX piperazine ring, and combine with it to form - $\mathrm{NH}_{2}^{+}$, forming a salt.

\section{3. (Powder X-Ray Diffraction, PXRD) Analysis}

When feeding at $1: 1$, new characteristic peaks appeared in the images at 5.64, $12.00,14.84,17.08,19.92,25.88$ and 27.96 degrees. When feeding at $2: 1$, new characteristic peaks appeared at 5.72, 12.08, 14.92, 17.12, 20.00, 25.96 and 28.12 degrees. When feeding at 1:2, new characteristic peaks appeared at 5.64, 12.00, $14.84,17.06,19.94,25.88$ and 27.96 degrees. The characteristic peaks, on the whole, seem to be very similar in their peak patterns, and the peaking angles are relatively close. However, the characteristic peaks of 10.56 degrees and 25.02 degrees attributed to NFX and 13.77 degrees, 19.54 degrees, 27.23 degrees and 37.34 degrees attributed to GLU disappeared. This is in line with the characteristics of the formation of new substances (salts), from which it can be speculated that there may be only one crystal form of salt formed when NFX and GLU are fed at 1:1, 1:2 and 2:1 (see Figure 3).

\subsection{Solubility Studies}

The $\mathrm{p} K_{\mathrm{a}}$ values of NFX and saturated aliphatic dicarboxylic acids used and solubility data for NFX and its salts are shown in Table 2 and Table 3. The solubility in pured water medium shows a clear increase in the solubility of the drug when in the form of of the carboxylate salts. Solubility of NFX was $0.343 \mathrm{mg} / \mathrm{mL}$, this is in agreement with the reference value $(0.28 \mathrm{mg} / \mathrm{mL})$ that indirectly validates our solubility method.

Table 2. $\mathrm{p} K_{\mathrm{a}}$ values of norfloxacin and saturated aliphatic dicarboxylic acids used.

\begin{tabular}{ccc}
\hline compound & $\mathrm{p} K_{\mathrm{a}}$ value & $\Delta \mathrm{p} K_{\mathrm{a}}($ NFX-acid $)$ \\
\hline NFX & 8.38 & $/$ \\
OXA & 1.27 & 7.11 \\
MAL & 2.85 & 5.53 \\
SUC & 4.21 & 4.17 \\
GLU & 4.34 & 4.04 \\
ADI & 4.41 & 3.97 \\
\hline
\end{tabular}


Table 3. Solubility Data for Norfloxacin and its salts.

\begin{tabular}{cc}
\hline Compoud & apparent solubility $(\mathrm{mg} / \mathrm{mL})$ \\
NFX & 0.343 \\
NFX-OXA & 2.504 \\
NFX-MAL & 3.970 \\
NFX-SUC & 7.099 \\
NFX-GLU & 27.695 \\
NFX-ADI & 11.761 \\
\hline
\end{tabular}

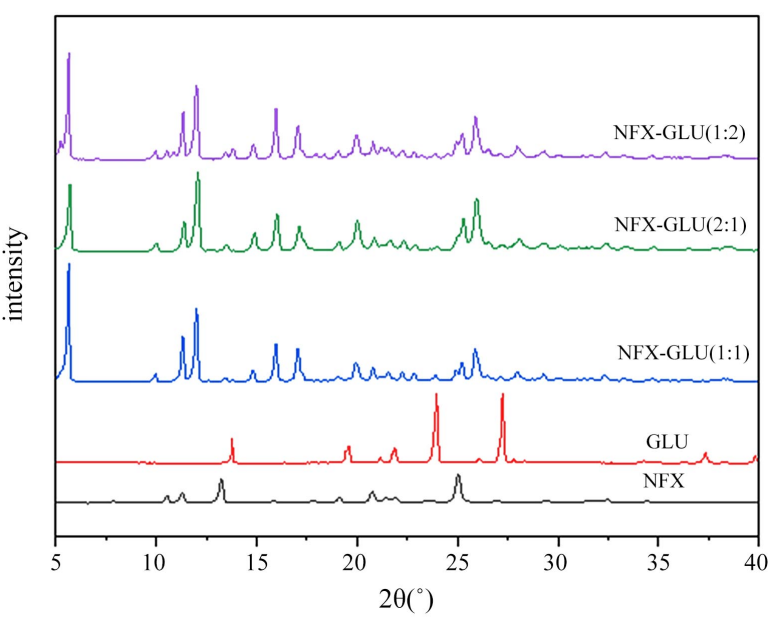

Figure 3. PXRD patterns of NFX, GLU, and their salts of 3 ratios.

The solubility of saturated aliphatic dicarboxylic acids salts was improved to 7.6 - 80.7 times. It is difficult to correlate solubility with $\mathrm{pKa}$ or $\Delta \mathrm{pKa}$. This may have a certain relationship with the accumulation of different crystals. Among them, the solubility of NFX glutarate is as high as $27.695 \mathrm{mg} / \mathrm{mL}$.

\section{Conclusion}

A series of norfloxacin salts of saturated aliphatic dicarboxylates were synthesized to confirm the proton transfer of hydrogen bonding and control their solubilities. The aqueous solubility of norfloxacin is increased after the formations of all salts. However, it is difficult to correlate solubility with $\mathrm{pKa}$ or $\Delta \mathrm{pKa}$. How the hydrogen-bonding interactions influence the solubility, crystal packing analyses still need to be carried out. It is anticipated that the bioavailability of norfloxacin may also be increased after the formation of such salts, and further studies on other fluoroquinolone salts are encouraged.

\section{Acknowledgements}

The financial support from Zhejiang Province Public Welfare Research Project (LGJ20B060001). 


\section{Conflicts of Interest}

The authors declare no conflicts of interest regarding the publication of this paper.

\section{References}

[1] Paulekuhn, G.S, Dressman, J.B. and Saal, C. (2007) Trends in Active Pharmaceutical Ingredient Salt Selection Based on Analysis of the Orange Book Database. Journal of Medicinal Chemistry, 50, 6665-6672. https://doi.org/10.1021/jm701032y

[2] Bastin, R.J., Bowker, M.J. and Slater, B.J. (2000) Salt Selection and Optimisation Procedures for Pharmaceutical New Chemical Entities. Organic Process Research \& Development, 4, 427-435. https://doi.org/10.1021/op000018u

[3] Sanphui, P., Tothadi, S., Ganguly, S. and Desiraju, G.R. (2013) Salt and Cocrystals of Sildenafil with Dicarboxylic Acids: Solubility and Pharmacokinetic Advantage of the Glutarate Salt. Molecular Pharmaceutics, 10, 4687-4697. https://doi.org/10.1021/mp400516b

[4] Oates, J.A., Wood, A.J.J., Hooper, D.C. and Wolfson, J.S. (1991) Fluoroquinolone Antimicrobial Agents. New England Journal of Medicine, 324, 384-394. https://doi.org/10.1056/NEJM199102073240606

[5] Breda, S.A., Jimenez-Kairuz, A.F., Manzo, R.H. and Olivera, M.E. (2009) Solubility Behavior and Biopharmaceutical Classification of Novel High-Solubility Ciprofloxacin and Norfloxacin Pharmaceutical Derivatives. International Journal of Pharmaceutics, 371, 106-113. https://doi.org/10.1016/j.ijpharm.2008.12.026

[6] Basavoju, S., Boström, D. and Velaga, S.P. (2006) Pharmaceutical Cocrystal and Salts of Norfloxacin. Crystal Growth \& Design, 6, 2699-2708.

https://doi.org/10.1021/cg060327x

[7] Surov, A.O., Voronin, A.P., Drozd, K.V., Churakov, A.V., Roussel, P. and Perlovich, G.L. (2018) Diversity of Crystal Structures and Physicochemical Properties of Ciprofloxacin and Norfloxacin Salts with Fumaric Acid. CrystEngComm, 20, 755-767. https://doi.org/10.1039/C7CE02033C

[8] Basavoju, S., Boström, D. and Velaga, S.P. (2012) Pharmaceutical Salts of Fluoroquinolone Antibacterial Drugs with Acesulfame Sweetener. Molecular Crystals and Liquid Crystals, 562, 254-264. https://doi.org/10.1080/10426507.2012.669673

[9] Huang, X.-F., Zhang, Z.-H., Zhang, Q.-Q., Wang, L.-Z., He, M.-Y., Chen, Q., et al. (2013) Norfloxacin Salts with Benzenedicarboxylic Acids: Charge-Assisted Hydrogen-Bonding Recognition and Solubility Regulation. CrystEngComm, 15, 6090-6100. https://doi.org/10.1039/c3ce40567b

[10] Bhattacharya, B., Mondal, A., Soni, S.R., Das, S., Bhunia, S., Bal Raju, K., et al. (2018) Multidrug Salt Forms of Norfloxacin with Non-Steroidal Anti-Inflammatory Drugs: Solubility and Membrane Permeability Studies. CrystEngComm, 20, 6420-6429. https://doi.org/10.1039/C8CE00900G

[11] Romañuk, C.B., Manzo, R.H., Linck, Y.G., Chattah, A.K., Monti, G.A. and Olivera, M.E. (2009) Characterization of the Solubility and Solid-State Properties of Saccharin Salts of Fluoroquinolones. Journal of Pharmaceutical Sciences, 98, 3788-3801. https://doi.org/10.1002/jps.21688

[12] Gopi, S.P., Ganguly, S. and Desiraju, G.R. (2016) A Drug-Drug Salt Hydrate of Norfloxacin and Sulfathiazole: Enhancement of in Vitro Biological Properties via Improved Physicochemical Properties. Molecular Pharmaceutics, 13, 3590-3594. https://doi.org/10.1021/acs.molpharmaceut.6b00320 
[13] Xu, Y., Jiang, L. and Mei, X. (2014) Supramolecular Structures and Physicochemical Properties of Norfloxacin Salts. Acta Crystallographica Section B, B70, 750-760. https://doi.org/10.1107/S2052520614011718

[14] Reddy, J.S., Ganesh, S.V., Nagalapalli, R., Dandela, R., Solomon, K.A., Kumar, K.A. and Nangia, A. (2011) Fluoroquinolone Salts with Carboxylic Acids. Journal of Pharmaceutical Sciences, 100, 3160-3176. https://doi.org/10.1002/jps.22537 